\title{
AVALIAÇÕES DE RISCO EM BARRAGENS: ESTUDO DE CASO DA BARRAGEM MALCOZINHADO NO NORDESTE BRASILEIRO
}

\author{
Risk Assessments of Dams: Case Study of the Malcozinhado Dam in Brazilian \\ Northeast
}

\author{
Mariana Campos Fontenelle ${ }^{1}$, Alexandre de Sousa Fontenelle ${ }^{2}$, Yago Machado Pereira de \\ Matos ${ }^{3}$, Fernando Feitosa Monteiro ${ }^{4}$
}

Recebido em 11 de abril de 2017; recebido para revisão em 20 de junho de 2017; aceito em 02 de agosto de 2017; disponível on-line em 25 de agosto de 2017.

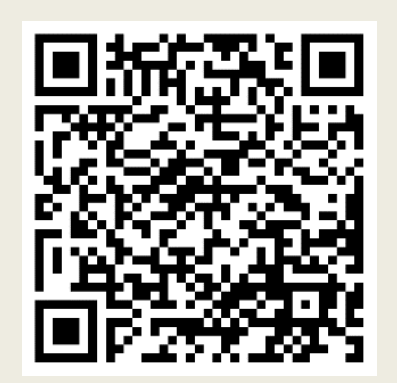

PALAVRAS CHAVE:

Material asfáltico;

Meio ambiente;

Pavimentação;

Resíduo;

Mineração.

\section{KEYWORDS:}

Asphaltic material;

Environment;

Paving;

Resudue;

Mining.

RESUMO: O presente trabalho tem a proposta de avaliar a eficácia de duas metodologias de avaliação de risco de uma barragem no Nordeste Brasileiro no intervalo de 10 anos, baseando-se na inspeção e no nível de ameaça. Utiliza-se a metodologia Nível de Perigo da Barragem (NPB) para cálculo do nível de ameaça (Fontenelle, 2007) e para o cálculo do risco as metodologias da Companhia de Gestão dos Recursos Hídricos do Ceará (COGERH) e do Conselho Nacional de Recursos Hídricos (CNRH). Observa-se que o crescente número de barragens somase a preocupação com a segurança destas. Face a isto, utiliza-se a avaliação de risco como forma de priorizar ações de manutenção e recuperação. O estudo de caso ocorreu na Barragem Malcozinhado, localizada no município de Cascavel, no estado do Ceará. Com base na inspeção, calcula-se o nível de ameaça e o risco, compara-se estes com os resultados de 2006. Assim, observou-se o aumento no nível de ameaça, no entanto, o risco permaneceu, em geral, baixo, semelhante aos resultados de 2006. Este resultado se deve ao fato de que o número de anomalias aumentou, porém trata-se de uma barragem jovem, de pequeno porte e inspecionada regularmente.

ABSTRACT: The present study has the proposal of evaluating the effectiveness of two methodologies of risk Assessment of a Brazilian Northeast dam in a range of 10 years, based on the inspection and the level of hazard. The methodology used for calculating the hazard level is the Dam Hazard Level (NPB). In addiction, in order to evaluate the risk is used the methodology of the Water Resources Management Company of Ceará (COGERH) and the methodology of National Resources Council Water (CNRH). The number of dams is increasing with to the concern for their safety. In view of this, risk assessment is used as a tool to prioritizing maintenance and recovery actions. The case study occurred in the Malcozinhado Dam, located in the municipality of Cascavel, in the state of Ceará. Based on the inspection, the level of hazard and risk is calculated, compared to the results for 2006. Thus, the increase in the level of hazard was observed, but the risk remained generally low, similar to 2006 result. This result is due to the fact that the number of anomalies has increased, but it is a young, small and regularly inspected dam.

\footnotetext{
* Contato com o autor:

${ }^{1}$ e-mail: marianacfontenelle@gmail.com (M. C. Fontenelle)

Eng. Civil, Universidade de Fortaleza (UNIFOR).

2 e-mail: alexandre.engineer@gmail.com (A. S. Fontenelle)

Eng. Civil, Doutor, Especialista em Infraestrutura Sênior do Ministério da Integração Nacional.

${ }^{3}$ e-mail: yago_mpm@hotmail.com (Y. M. P. Matos)

Eng. Civil, Mestrando na Universidade Federal do Ceará (UFC).

${ }^{4}$ e-mail: engffmonteiro@gmail.com (F. F. Monteiro)

Eng. Civil, Mestre, Doutorando na Universidade de Brasília (UnB).
} 


\section{INTRODUÇÃO}

As barragens podem ter diversos usos $\mathrm{e}$ finalidades de acordo com a necessidade da população da região, como por exemplo, para geração de energia, regularização de um rio, controle de enchentes e armazenamento de água. Devido ao seu múltiplo uso, este tipo de obra se torna comum no mundo inteiro. No semiárido brasileiro, a barragem tem sido o principal mecanismo para o combate aos efeitos da seca, pois é capaz de armazenar grandes volumes de água para uso posterior.

Entretanto, o aumento do número de barragens também torna crescente a preocupação com a segurança deste tipo de estrutura. Grandes acidentes com barragens chamaram atenção para este problema, haja vista que a falha destas estruturas pode deixar áreas inundadas, plantações dizimadas e causar mortes de populações e animais.

No Brasil, como forma de minimizar o risco de uma barragem, são executadas inspeções periódicas objetivadas na identificação de anomalias no barramento e suas estruturas auxiliares. Com base em inspeções, é realizada a avaliação de risco da barragem, de modo a ser o principal instrumento para a prevenção de possíveis acidentes.

\section{OBJETIVO}

A pretensão do presente trabalho é avaliar a eficácia de duas metodologias de avaliação de risco existentes, baseando-se em inspeções e no nível de ameaça, considerando o comportamento de um barramento em um intervalo de 10 anos, de 2006 a 2016.

\section{GESTÃO DE SEGURANÇA DE BARRAGENS}

Segundo Menescal (2009), aspectos como o aumento de comunidades nos vales dos rios, ocorrência de rupturas e envelhecimento de

\footnotetext{
${ }^{1}$ BRASIL. Ministério da integração Nacional. Manual de Segurança e Inspeção de Barragens. Brasília. 2002. 148p.
}

barragens, provocaram uma crescente preocupação internacional com o tema segurança de barragens desde os anos de 1950 e 1960. A segurança de obras de barramento consiste em manter os níveis admissíveis de risco à sociedade e ao meio ambiente, adotando comportamentos para evitar incidentes e acidentes que possam prejudicar em aspectos estruturais, econômicos, ambientais e sociais (BRASIL ${ }^{1}, 2002$ apud FONTENELLE, 2007).

Neste contexto, faz-se necessária a atuação dos órgãos competentes na gestão de segurança de barragens, visando englobar os seguintes fatores: hidráulico-operacionais, estruturais, ambientais, sociais e econômicos (INAG, 2001). Por exemplo, deve-se aliar a estabilidade estrutural das obras, o bom funcionamento dos equipamentos hidráulicos e a minimização dos impactos nas populações, fauna e flora atingidos com a construção de uma barragem.

Destaca-se que parte dos problemas relacionados à segurança de barragens podem ser evitados por medidas preventivas relacionadas ao projeto, construção e operação. Deve-se então inspecionar as obras ao longo da sua existência com o intuito de ter consciência acerca de qualquer ameaça. Adotam-se ações classificadas em estruturais: como reforço de estruturas, e não estruturais: monitoramento da instrumentação e inspeções através de check-lists por técnicos qualificados, como forma de minimizar os riscos deste tipo de estrutura (FONTENELLE, 2007).

\section{ANÁLISE DE RISCO}

Segundo Mello (2010), pode-se definir risco como a combinação da probabilidade de ocorrência de um evento com suas consequências. A probabilidade de ocorrência de um evento é geralmente intitulada como ameaça e as consequências são os custos diretos e indiretos decorrentes da manifestação de ameaça. No item 4.1 apresenta-se a metodologia Nível de Perigo da Barragem (NPB) (FONTENELLE, 2007), como 
exemplo de metodologia associada apenas à ameaça, tendo em vista que seu cálculo é efetuado considerando o número de anomalias verificadas durante a inspeção e os respectivos Níveis de Perigo (NP).

O risco está presente em qualquer obra de engenharia, pois não é possível determinar por completo o comportamento de alguns materiais, como por exemplo, o solo. Desta forma, as estruturas devem estar em constante monitoramento, visando gerenciar ou minimizar o risco.

Segundo Fontenelle (2007), o risco depende de fatores intrínsecos à barragem, de Natureza física e/ou socioeconômica. Por exemplo, é função dos fatores intrínsecos da barragem onde se destacam o controle de construção e operação, de fatores de natureza física o regime hidrológico da região e, por fim, o porte da cidade que se encontra à jusante é um dos principais fatores socioeconômicos.

Calcula-se o risco em função dos danos, da probabilidade e das consequências dos possíveis eventos (MEDEIROS ${ }^{2}$, 2005 apud FONTENELLE, 2007). Desta forma, estes podem ser classificados em elevado, significativo ou baixo quanto a magnitude com que afeta vidas humanas e custos materiais (FONTENELLE, 2007).

A análise de risco utiliza a avalição de risco como forma de coletar dados para a análise da situação da segurança da barragem. A avaliação de risco, por sua vez, tem como objetivos básicos identificar as ameaças em potencial e os modos de ruptura, proceder a uma estimativa estatística de risco, avaliar tolerabilidade, avaliar o potencial de redução através de medidas corretivas eventualmente necessárias e estabelecer uma estratégia de atenuação (SILVEIRA ${ }^{3}, 2007$ apud FONTENELLE, 2007).

\footnotetext{
${ }^{2}$ MEDEIROS, C. H. de A. C . How Risky can be a Risk Assessment Technique on Safety Dams Evaluation - $A$ Critical Review. In: 73rd Annual Meeting, ICOLD, Teerã, 2005.
}

A classificação das barragens em função do risco é uma ferramenta importante a ser utilizada para administrar o investimento em ações de prevenção de acidentes, priorizando as ações de recuperação e reforço nas barragens que apresentarem um maior risco.

\subsection{NÍVEL DE AMEAÇA}

Conforme a metodologia proposta por Fontenelle (2007), os valores provenientes do NP podem ser utilizados para o cálculo da probabilidade de ruptura (ameaça) utilizando-se o chamado Nível de Perigo da Barragem (NPB). Para o cálculo, inicialmente, são atribuídos pesos para cada um dos NP, conforme mostra-se no Quadro 1, valendo ressaltar que os números entre parêntesis indicam a numeração utilizada na coluna NP da lista de inspeção.

QUADRO 1: O Níveis de Perigo e os Pesos respectivos.

\begin{tabular}{|c|c|}
\hline Nível de Perigo da Anomalia & Peso do NP (a) \\
\hline Nenhum (0) & 0 \\
\hline Atenção (1) & 1 \\
\hline Alerta (2) & 4 \\
\hline Emergência (3) & 9 \\
\hline
\end{tabular}

FONTE: FONTENELLE, 2007.

Em seguida, deve-se levantar as quantidades de NP em cada nível e efetuar uma segunda ponderação de acordo com o Quadro 2.

QUADRO 2: Peso da quantidade de NP em cada nível.

\begin{tabular}{|c|c|}
\hline $\begin{array}{c}\text { Quantidade de NP na lista de } \\
\text { inspeção }\end{array}$ & $\begin{array}{c}\text { Peso da } \\
\text { quantidade }\end{array}$ \\
\hline $0-5$ & 1 \\
\hline $6-10$ & 2 \\
\hline $11-15$ & 3 \\
\hline $16-20$ & 4 \\
\hline $21-35$ & 5 \\
\hline $36-50$ & 6 \\
\hline
\end{tabular}

FONTE: FONTENELLE, 2007.

${ }^{3}$ SILVEIRA, J.F.; CARNEIRO, E. F.; PÍNFARI J. C. O Grande Potencial Apresentado pela Análise de Risco de Usinas Hidrelétricas - A Experiência da CESP. XXVII Seminário Nacional De Grandes Barragens. Belém - Pa, 2007. 
Por fim, calcula-se o NPB por meio do somatório dos produtos entre o peso do NP e o peso das quantidades de anomalias encontradas em cada NP durante a inspeção (FONTENELLE, 2007). Utilizase, geralmente, o Quadro 3 como o apresentado a seguir, para o cálculo de NPB total da Barragem.

As barragens são classificadas, ainda, quanto ao NPB no desempenho da estrutura em operação, como é possível se observar no Quadro 4.

\subsection{TIPOS DE AVALIAÇÃO DE RISCO}

Para se evitar possíveis eventos, como os citados anteriormente, ocasionados pela manutenção inadequada de uma barragem, desenvolvem-se metodologias de avaliação de risco, visando adequar-se a cada necessidade de análise.

\subsubsection{Metodologia da Companhia de Gestão e} Recursos Hídricos do Estado do Ceará (COGERH)

Instituída em 2001 pela COGERH (MENESCAL et al., 2001), esta metodologia utiliza três parâmetros para calcular o potencial de risco $(P R)$. São os parâmetros: a Periculosidade (P),
Vulnerabilidade (V) e a Importância Estratégica (I). A Periculosidade engloba dados técnicos e de construção, calculada a partir do somatório dos índices de acordo com os critérios e pontuações do Quadro 5. Sendo considerada elevada se a pontuação for maior que 30 , significativo para uma pontuação entre 20 e 30 e baixo a moderado para pontuações entre 10 e 20.

Com base em inspeções de campo e em leituras de instrumentação, tais como piezômetros e medidores de recalques magnéticos, é calculada a estimativa de Vulnerabilidade (V) segundo o Quadro 6, e a partir de critérios econômicos, técnicos, ambientais e sociais é estabelecida a importância estratégica (I) com base no Quadro 7 (FONTENELLE, 2007).

A Vulnerabilidade é dada pela soma dos índices da tabela e pode ser classificada em: elevada se for maior que 35, moderada a elevada se for entre 20 e 35, baixa a moderada se for entre 5 e 20 e muito baixa se menor que 5. A importância estratégica (I), por sua vez, é dada pela média aritmética dos valores.

\begin{tabular}{|c|l|l|l|l|}
\hline \multicolumn{5}{|c|}{ QUADRO 3: Exemplo de Quadro utilizado para o cálculo da pontuação total do NPB. } \\
\hline NP & Peso do NP (a) & $\begin{array}{c}\text { Quantidade na } \\
\text { lista de Inspeção }\end{array}$ & $\begin{array}{c}\text { Peso das Quantidades } \\
\text { (b) }\end{array}$ & Pontuação NPB (a x b) \\
\hline Nenhum(0) & & & & \\
\hline Atenção (1) & & & & \\
\hline Alerta(2) & & \multicolumn{3}{|c|}{ Total da pontuação NPB da barragem = } \\
\hline Emergência (3) & & FONTE: FONTENELLE, 2007. \\
\hline \multicolumn{7}{|c|}{}
\end{tabular}

\begin{tabular}{|c|c|}
\hline \multicolumn{2}{|c|}{ QUADRO 4: Classificação da Barragem adotada a partir do NPB. } \\
\hline NPB & Classificação \\
\hline$>30$ & Altamente preocupante (AP) \\
\hline $9-30$ & Preocupante (P) \\
\hline $2-8$ & Aceitável (Ac) \\
\hline 1 & Bom Desempenho (BD) \\
\hline 0 & Ótimo Desempenho (OD) \\
\hline
\end{tabular}


QUADRO 5: Periculosidade (P).

\begin{tabular}{|c|c|c|c|c|}
\hline DIMENSÃO DA BARRAGEM ${ }^{1}$ & $\begin{array}{l}\text { VOL. TOTAL DO } \\
\text { RESERVATÓRIO }{ }^{2}\end{array}$ & $\begin{array}{c}\text { TIPO DE } \\
\text { BARRAGEM }^{3}\end{array}$ & $\begin{array}{c}\text { TIPO DE } \\
\text { FUNDAÇÃ̃O }\end{array}$ & VAZÃO DE PROJETO ${ }^{5}$ \\
\hline $\begin{array}{c}\text { Altura } \leq 10 \mathrm{~m} \text { Comprimento } \leq \\
200 \mathrm{~m}(1)\end{array}$ & $\begin{array}{l}\text { Pequeno } \\
<20 \mathrm{hm}^{3}(3) \\
\end{array}$ & $\begin{array}{c}\text { Concreto } \\
(4)\end{array}$ & $\begin{array}{l}\text { Rocha } \\
\text { (1) }\end{array}$ & Decamilenar (1) \\
\hline $\begin{array}{c}\text { Altura } 10 \text { a } 20 \mathrm{~m} \\
\text { Comprimento } \leq 2000 \mathrm{~m} \text { (3) }\end{array}$ & $\begin{array}{l}\text { Médio até } \\
200 \mathrm{hm}^{3} \\
(5)\end{array}$ & $\begin{array}{c}\text { Alvenaria de pedra } \\
\text { / Concreto rolado } \\
\text { (6) }\end{array}$ & $\begin{array}{l}\text { Rocha alterada / } \\
\text { Saprolito (4) }\end{array}$ & $\begin{array}{l}\text { Milenar } \\
\text { (2) }\end{array}$ \\
\hline $\begin{array}{c}\text { Altura } 20 \text { a } 50 \mathrm{~m} \\
\text { Comprimento } 200 \mathrm{~m} \text { a } \\
3000 \mathrm{~m}(6)\end{array}$ & $\begin{array}{c}\text { Regular } \\
200 \text { a } 800 \mathrm{hm}^{3} \\
\text { (7) }\end{array}$ & $\begin{array}{c}\text { Terra / } \\
\text { Enrocamento } \\
(8)\end{array}$ & $\begin{array}{c}\text { Solo residual / } \\
\text { Aluvião até } 4 \mathrm{~m} \text { (5) }\end{array}$ & $\begin{array}{l}500 \text { anos } \\
\text { (4) }\end{array}$ \\
\hline $\begin{array}{l}\text { Altura }>50 \mathrm{~m} \\
\text { Comprimento }>500 \mathrm{~m}(10)\end{array}$ & $\begin{array}{c}\text { Muito grande > } \\
800 \mathrm{hm}^{3} \\
(10)\end{array}$ & $\begin{array}{c}\text { Terra } \\
(10)\end{array}$ & $\begin{array}{l}\text { Aluvião arenoso } \\
\text { espesso / Solo } \\
\text { orgânico (10) }\end{array}$ & $\begin{array}{c}\text { Inferior a } 500 \text { anos ou } \\
\text { Desconhecida } \\
(10)\end{array}$ \\
\hline
\end{tabular}

\begin{tabular}{|c|c|c|c|c|c|c|}
\hline \multicolumn{7}{|c|}{ QUADRO 6: Vulnerabilidade (V). } \\
\hline $\begin{array}{l}\text { TEMPO } \\
\text { DE OPERA- } \\
\text { ÇÃO } \\
\end{array}$ & $\begin{array}{c}\text { EXISTÊNCIA DE } \\
\text { PROJETO (AS } \\
\text { BUILT) }\end{array}$ & $\begin{array}{l}\text { CONFIA- } \\
\text { BILIDADE- } \\
\text { DAS ESTRU- } \\
\text { TURAS } \\
\text { VERTEDOU- } \\
\text { RAS }^{8}\end{array}$ & $\begin{array}{c}\text { TOMADA } \\
\text { DE ÁGUA } \\
9\end{array}$ & $\begin{array}{c}\text { PERCOLAÇÃO } \\
10\end{array}$ & $\begin{array}{l}\text { DEFOR- } \\
\text { MAÇÕES/ } \\
\text { AFUNDA- } \\
\text { MENTOS } \\
\text { ASSENTA- } \\
\text { MENTOS } \\
\text { M1 }\end{array}$ & $\begin{array}{l}\text { DETERIORAÇÃO DOS } \\
\text { TALUDES/ } \\
\text { PARAMENTOS }{ }^{12}\end{array}$ \\
\hline$>30$ anos $(0)$ & $\begin{array}{c}\text { Existem pro- } \\
\text { jetos "as built" } \\
\text { e avaliação do } \\
\text { desempenho } \\
\text { (1) }\end{array}$ & $\begin{array}{l}\text { Muito Sa- } \\
\text { tisfatória (2) }\end{array}$ & $\begin{array}{l}\text { Satisfató- } \\
\text { ria } \\
\text { Controle a } \\
\text { montante } \\
(1) \\
\end{array}$ & $\begin{array}{c}\text { Totalmente } \\
\text { Controlada } \\
\text { Pelo sistema de } \\
\text { drenagem (1) }\end{array}$ & Inexistente (0) & Inexistente (1) \\
\hline $\begin{array}{c}10 \text { a } 30 \text { anos } \\
\text { (1) }\end{array}$ & $\begin{array}{l}\text { Existem } \\
\text { projetos "as } \\
\text { built" (3) }\end{array}$ & $\begin{array}{l}\text { Satisfatória } \\
\text { (3) }\end{array}$ & $\begin{array}{l}\text { Satisfató- } \\
\text { ria } \\
\text { Controle a } \\
\text { jusante } \\
\text { (2) }\end{array}$ & $\begin{array}{c}\text { Sinais de } \\
\text { umedecimento } \\
\text { nas áreas de } \\
\text { jusante, ta- } \\
\text { ludes ou } \\
\text { ombreiras (4) }\end{array}$ & $\begin{array}{l}\text { Pequenos } \\
\text { abatimentos da } \\
\text { crista (2) }\end{array}$ & $\begin{array}{l}\text { Falhas no rip-rap e } \\
\text { na proteção de } \\
\text { Jusante (3) }\end{array}$ \\
\hline $\begin{array}{c}5 \text { a } 10 \text { anos } \\
\text { (2) }\end{array}$ & $\begin{array}{l}\text { Só projeto } \\
\text { básico (5) }\end{array}$ & Suficiente (6) & $\begin{array}{l}\text { Aceitável } \\
\text { (3) }\end{array}$ & $\begin{array}{c}\text { Zonas úmidas } \\
\text { em taludes de } \\
\text { jusante, } \\
\text { ombreiras, } \\
\text { área alagada a } \\
\text { jusante devida } \\
\text { ao fluxo (6) }\end{array}$ & $\begin{array}{l}\text { Ondulações } \\
\text { pronunciadas, } \\
\text { Fissuras (6) }\end{array}$ & $\begin{array}{l}\text { Falha nas proteções } \\
\text { - drenagens insufi- } \\
\text { ciente e sulcos nos } \\
\text { taludes. (7) }\end{array}$ \\
\hline$<5$ anos (3) & $\begin{array}{l}\text { Não existe } \\
\text { projeto (7) }\end{array}$ & $\begin{array}{l}\text { Não satis- } \\
\text { fatório (10) }\end{array}$ & $\begin{array}{l}\text { Deficiente } \\
\text { (5) }\end{array}$ & $\begin{array}{l}\text { Surgência de } \\
\text { água em talu- } \\
\text { des, ombreiras } \\
\text { e área de ju- } \\
\text { sante (10) }\end{array}$ & $\begin{array}{l}\text { Depressão na } \\
\quad \text { crista - } \\
\text { Afundamentos } \\
\text { nos taludes, ou } \\
\text { na fundação } \\
\text { /Trincas (10) }\end{array}$ & $\begin{array}{l}\text { Depressão no rip- } \\
\text { rap Escorrega- } \\
\text { mentos - sulcos } \\
\text { profundos de } \\
\text { Erosão, Vegetação } \\
(10)\end{array}$ \\
\hline
\end{tabular}

FONTE: FONTENELLE, 2007.

\begin{tabular}{|c|c|c|}
\hline \multicolumn{3}{|c|}{ QUADRO 7: Importância Estratégica (I). } \\
\hline VOL. ÚTIL ${ }^{1} \mathrm{hm}^{3}$ (A) & POPULAÇÃO A JUSANTE ${ }^{\text {(B) }}$ & CUSTO DA BARRAGEM ${ }^{(C)}$ \\
\hline Grande $(2)>800$ & Grande $(2,5)$ & Elevado $(1,5)$ \\
\hline Médio $(1,5) 200$ a 800 & Média $(2,0)$ & Médio (1,2) \\
\hline Baixo (1) $<200$ & Pequena (1,0) & Pequeno (1,0) \\
\hline
\end{tabular}


O Potencial de Risco (PR) é então calculado por meio da Equação 1:

$$
P R=\frac{(P+V)}{2} \times I
$$

Em que:

PR = Potencial de Risco;

$\mathbf{P}=$ Periculosidade;

$\mathbf{V}=$ Vulnerabilidade;
I = Importância Estratégica.

Após o cálculo do PR, aplica-se o valor no Quadro 8, a fim de determinar a faixa de classificação de risco em que a barragem encontrase. Com base nessa classificação, os Quadros 9, 10 e 11 indicam a frequência das inspeções, requisitos mínimos quanto à manutenção e aos critérios de instrumentação, respectivamente (FONTENELLE, 2007).

QUADRO 8: Classificação quanto à classe de risco da barragem baseada no valor do PR.

\begin{tabular}{|c|c|}
\hline CLASSE & PR \\
\hline A & $>65$ (ou Vi=10) - alto \\
\hline B & 40 a $65-$ médio \\
\hline C & 25 a $40-$ normal \\
\hline D & 15 a $25-$ baixo \\
\hline E & $<15-$ muito baixo \\
\hline
\end{tabular}

FONTE: FONTENELLE, 2007.

\begin{tabular}{|c|c|c|c|c|c|}
\hline \multicolumn{6}{|c|}{ QUADRO 9: Frequência de inspeções. } \\
\hline $\begin{array}{c}\text { TIPO DE } \\
\text { INSPEÇÃO }\end{array}$ & $\mathrm{A}$ & $\mathrm{B}$ & $\mathrm{C}$ & $\mathrm{D}$ & \multicolumn{1}{c|}{ CLASSIFICAÇÃO DA BARRAGEM } \\
\hline Rotina & & $12 /$ ano (mensal) & $4 /$ ano (trimestral) & $2 /$ ano (semestral) & $1 /$ ano (anual) \\
\hline Periódica & & $\begin{array}{c}1 / \text { ano (relatório } \\
\text { completo) }\end{array}$ & $\begin{array}{c}1 / \text { ano (relatório } \\
\text { simplificado), } 1 / 2 \text { anos } \\
\text { (relatório completo) }\end{array}$ & $\begin{array}{c}1 / 2 \text { anos (relatório } \\
\text { simplificado) }\end{array}$ & $\begin{array}{c}1 / 4 \text { anos (relatório } \\
\text { simplificado) }\end{array}$ \\
\hline Formal & Para definir \\
Especial & $\begin{array}{c}\text { intervenção e } \\
\text { reclassificação }\end{array}$ & $\begin{array}{c}\text { Em oportunidades tais como cheias excepcionais, rebaixamento rápido do } \\
\text { reservatório, sismos etc. }\end{array}$ \\
\hline Emergência & \multicolumn{5}{|c|}{ Após eventos de magnitude especial. } \\
\hline
\end{tabular}

FONTE: FONTENELLE, 2007.

\begin{tabular}{|c|c|}
\hline \multicolumn{2}{|c|}{ QUADRO 10: Requisitos mínimos quanto à manutenção. } \\
\hline CLASSE DA BARRAGEM & REQUISITOS MíNIMOS \\
\hline A & Intervenção e Reclassificação \\
\hline B & I-deficiências inexistentes ou irrelevantes \\
\hline C & P- pequenas deficiências \\
\hline D & P- pequenas deficiências \\
\hline E & M - deficiências médias \\
\hline
\end{tabular}

QUADRO 11: Critério para Instrumentação da Barragem Malcozinhado.

\begin{tabular}{|c|c|c|c|c|c|}
\hline \multicolumn{2}{|c|}{ Altura da Barragem (m) } & $<10$ & 10 a 20 & 20 a 50 & $>50$ \\
\hline \multirow{2}{*}{ Deslocamento } & Superficial & - & $(x)$ & $\mathrm{x}$, se classe $\mathrm{B}$ ou $\mathrm{I}=2$ & $x$ \\
\hline & Interno & - & - & - & $(x)$ \\
\hline \multicolumn{2}{|c|}{ Tensões totais } & - & - & - & $(x)$ \\
\hline \multicolumn{2}{|c|}{ Vazões } & - & $(x)$ & $\begin{array}{c}\text { x, vazão total se classe } \\
\text { B ou l=2 }\end{array}$ & $\begin{array}{c}\text { (x), vazão parcial ou x } \\
\text { vazão total }\end{array}$ \\
\hline \multicolumn{2}{|c|}{ Piezômetros } & - & $(x)$ & $\mathrm{x}$, se clas-se $\mathrm{B}$ ou $\mathrm{I}=2$ & $x$ \\
\hline \multicolumn{2}{|c|}{ Sismologia } & - & - & $(x)$ & $\mathrm{X}$, se classe $\mathrm{B}$ ou $\mathrm{I}=2$ \\
\hline
\end{tabular}

NOTA:

$x$ - Dispositivo obrigatório

$(x)$ - Dispositivo opcional 


\subsubsection{Metodologia do Conselho Nacional de Recursos Hídricos (CNRH)}

Alicerçado na metodologia da COGERH, este método é utilizado para classificação das barragens de usos múltiplos no âmbito da União. Segundo ANDERÁOS, ARAÚJO e NUNES (2013) a Resolução CNRH no 143, de 10 de julho de 2012 estabelece os critérios de classificação quanto à Categoria de Risco (CRI) e Dano Potencial Associado (DPA) para a determinação do nível de risco utilizando a Matriz de Categoria de Risco e Dano
Potencial Associado constante no Anexo I da Resolução Agência Nacional de Águas (ANA) no 236/2017.

Quanto à CRI, esta é calculada a partir da soma dos seguintes critérios para classificação: Características Técnicas (CT), Estado de Conservação (EC) e Plano de Segurança da Barragem (PS), com os parâmetros e pontuações dispostos nos Quadros 12, 13 e 14. Para o cálculo do DPA adotamse os parâmetros e pontuações do Quadro 15.

\begin{tabular}{|c|c|c|c|c|c|}
\hline \multicolumn{6}{|c|}{ QUADRO 12: Características Técnicas (CT). } \\
\hline Aspecto & \multicolumn{5}{|c|}{ Descrição da Característica Técnica } \\
\hline Altura (a) & Altura $\leq 15 \mathrm{~m}(0)$ & $15 \mathrm{~m}<$ Altura $<30 \mathrm{~m}(1)$ & $\begin{array}{c}30 \mathrm{~m} \leq \text { Altura } \leq \\
60 \mathrm{~m}(2)\end{array}$ & Altura > 60m (3) & - \\
\hline $\begin{array}{c}\text { Comprimento } \\
\text { (b) }\end{array}$ & $\begin{array}{c}\text { Comprimento } \leq \\
200 \mathrm{~m}(2)\end{array}$ & Comprimento $>200 \mathrm{~m}(3)$ & - & - & - \\
\hline $\begin{array}{c}\text { Tipo de } \\
\text { Barragem } \\
\text { quanto ao } \\
\text { material de } \\
\text { construção(c) }\end{array}$ & $\begin{array}{c}\text { Concreto } \\
\text { convencional (1) }\end{array}$ & $\begin{array}{c}\text { Alvenaria de Pedra / } \\
\text { Concreto Ciclópico / } \\
\text { Concreto Rolado - CCR (2) }\end{array}$ & $\begin{array}{c}\text { Terra Homogênea } \\
\text { / Enrocamento / } \\
\text { Terra } \\
\text { Enrocamento (3) }\end{array}$ & - & - \\
\hline $\begin{array}{c}\text { Tipo de } \\
\text { fundação (d) }\end{array}$ & Rocha sã (1) & $\begin{array}{l}\text { Rocha altamente dura } \\
\text { com tratamento (2) }\end{array}$ & $\begin{array}{c}\text { Rocha alterada } \\
\text { sem tratamento / } \\
\text { Rocha altamente } \\
\text { fraturada com } \\
\text { tratamento (3) }\end{array}$ & $\begin{array}{l}\text { Rocha alterada } \\
\text { mole/ Saprolito / } \\
\text { Solo compacto (4) }\end{array}$ & $\begin{array}{l}\text { Solo } \\
\text { residual/ } \\
\text { aluvião } \\
\text { (5) }\end{array}$ \\
\hline $\begin{array}{c}\text { Idade da } \\
\text { Barragem (e) }\end{array}$ & $\begin{array}{l}\text { Entre } 30 \text { e } 50 \\
\quad \operatorname{anos}(1)\end{array}$ & Entre 10 e 30 anos (2) & $\begin{array}{c}\text { Entre } 5 \text { e } 10 \text { anos } \\
\text { (3) }\end{array}$ & $\begin{array}{c}<5 \text { anos ou }>50 \\
\text { anos ou sem } \\
\text { informação (4) }\end{array}$ & - \\
\hline $\begin{array}{l}\text { Vazão de } \\
\text { Projeto (f) }\end{array}$ & $\begin{array}{l}\text { Decamilenar ou } \\
\text { CMP (Cheia } \\
\text { Máxima } \\
\text { Provável) - TR = } \\
10.000 \text { anos (3) }\end{array}$ & $\begin{array}{c}\text { Milenar }-\mathrm{TR}=1.000 \text { anos } \\
(5)\end{array}$ & $\mathrm{TR}=500$ anos $(8)$ & $\begin{array}{c}\text { TR }<500 \text { anos ou } \\
\text { Desconhecida / } \\
\text { Estudo não } \\
\text { confiável (10) }\end{array}$ & - \\
\hline
\end{tabular}

FONTE: ANDERÁOS, ARAÚJO E NUNES, 2013.

\begin{tabular}{|c|c|c|c|c|}
\hline Aspecto & & Descriçãc & o estado de conservação & \\
\hline $\begin{array}{c}\text { Confiabili- } \\
\text { dade das } \\
\text { Estruturas } \\
\text { Extravaso- } \\
\text { ras (g) }\end{array}$ & $\begin{array}{l}\text { Estruturas civis } \\
\text { e hidroeletro- } \\
\text { mecânicas em } \\
\text { pleno funciona- } \\
\text { mento / canais } \\
\text { de aproximação } \\
\text { ou de } \\
\text { restituição ou } \\
\text { vertedouro } \\
\text { (tipo soleira } \\
\text { livre) de- } \\
\text { sobstruídos (0) }\end{array}$ & $\begin{array}{c}\text { Estruturas civis e } \\
\text { hidroeletromecânicas } \\
\text { preparadas para a } \\
\text { operação, mas sem } \\
\text { fontes de suprimento } \\
\text { de energia de emer- } \\
\text { gência / canais ou } \\
\text { vertedouro (tipo soleira } \\
\text { livre) com erosões ou } \\
\text { obstruções, porém sem } \\
\text { riscos a estrutura } \\
\text { vertente. (4) }\end{array}$ & $\begin{array}{l}\text { Estruturas civis compro- } \\
\text { metidas ou dispositivos } \\
\text { hidroeletromecanicos com } \\
\text { problemas identificados, } \\
\text { com redução de capacidade } \\
\text { de vazão e com medidas } \\
\text { corretivas em implanta- } \\
\text { ção/canais ou vertedouro } \\
\text { (tipo soleira livre) com } \\
\text { erosões e/ou parcialmente } \\
\text { obstruídos, com risco de } \\
\text { comprometimento da estru- } \\
\text { tura vertente. (7) }\end{array}$ & $\begin{array}{c}\text { Estruturas civis } \\
\text { comprometidas ou } \\
\text { dispositivos } \\
\text { hidroeletromecanicos } \\
\text { com problemas } \\
\text { identificados, com } \\
\text { redução de capacidade } \\
\text { de vazão e sem me- } \\
\text { didas corretivas/canais } \\
\text { ou vertedouro (tipo } \\
\text { soleira livre) obstruídos } \\
\text { ou com estruturas } \\
\text { danificadas (10) }\end{array}$ \\
\hline
\end{tabular}


QUADRO 13: Estado de Conservação (EC). (CONTINUAÇÃO)

\begin{tabular}{|c|c|c|c|c|}
\hline Aspecto & \multicolumn{4}{|c|}{ Descrição do estado de conservação } \\
\hline $\begin{array}{l}\text { Confiabili- } \\
\text { dade das } \\
\text { Estruturas } \\
\text { de Adução } \\
\text { (h) }\end{array}$ & $\begin{array}{l}\text { Estruturas civis } \\
\text { e dispositivos } \\
\text { hidroeletro- } \\
\text { mecânicos em } \\
\text { condições ade- } \\
\text { quadas de } \\
\text { manutenção e } \\
\text { funcionamento } \\
(0)\end{array}$ & $\begin{array}{c}\text { Estruturas civis } \\
\text { comprometidas ou } \\
\text { dispositivos hi- } \\
\text { droeletromecânicos } \\
\text { com problemas } \\
\text { identificados, com } \\
\text { redução de capacidade } \\
\text { de vazão e com medidas } \\
\text { corretivas em } \\
\text { implantação (4) }\end{array}$ & $\begin{array}{c}\text { Estruturas civis } \\
\text { comprometidas ou } \\
\text { dispositivos } \\
\text { hidroeletromecânicos com } \\
\text { problemas identificados, } \\
\text { com redução de } \\
\text { capacidade de vazão e sem } \\
\text { medidas corretivas (6) }\end{array}$ & \\
\hline $\begin{array}{c}\text { Percolação } \\
\text { (i) }\end{array}$ & $\begin{array}{c}\text { Percolação } \\
\text { totalmente } \\
\text { controlada pelo } \\
\text { sistema de } \\
\text { drenagem (0) } \\
\end{array}$ & $\begin{array}{l}\text { Umidade ou surgência } \\
\text { nas áreas de jusante, } \\
\text { paramentos, taludes ou } \\
\text { ombreiras estabilizadas } \\
\text { e/ou monitoradas (3) }\end{array}$ & $\begin{array}{l}\text { Umidade ou surgência nas } \\
\text { áreas de jusante para- } \\
\text { mentos, taludes ou om- } \\
\text { breiras sem tratamento ou } \\
\text { em fase de diagnóstico (5) }\end{array}$ & $\begin{array}{l}\text { Surgência nas áreas de } \\
\text { jusante, taludes ou om- } \\
\text { breiras com carreamen- } \\
\text { to de material ou com } \\
\text { vazão crescente (8) }\end{array}$ \\
\hline $\begin{array}{l}\text { Deforma- } \\
\text { ções e Re- } \\
\text { calques (j) }\end{array}$ & Inexistente (0) & $\begin{array}{l}\text { Existência de trincas e } \\
\text { abatimentos de } \\
\text { pequena extensão e } \\
\text { impacto nulo (1) }\end{array}$ & $\begin{array}{l}\text { Existência de trincas e } \\
\text { abatimentos de impacto } \\
\text { considerável gerando } \\
\text { necessidade de estudos } \\
\text { adicionais ou } \\
\text { monitoramento (5) }\end{array}$ & $\begin{array}{l}\text { Existência de trincas, } \\
\text { abatimentos ou } \\
\text { escorregamentos } \\
\text { expressivos, com } \\
\text { potencial de com- } \\
\text { prometimento da } \\
\text { segurança (8) }\end{array}$ \\
\hline $\begin{array}{l}\text { Deterio- } \\
\text { ração dos } \\
\text { Taludes / } \\
\text { Paramentos } \\
\text { (I) }\end{array}$ & Inexistente (0) & $\begin{array}{l}\text { Falhas na proteção dos } \\
\text { taludes e paramentos, } \\
\text { presença de arbustos de } \\
\text { pequena extensão e } \\
\text { impacto nulo. (1) }\end{array}$ & $\begin{array}{c}\text { Erosões superficiais, } \\
\text { ferragem exposta, cresci- } \\
\text { mento de vegetação } \\
\text { generalizada, gerando } \\
\text { necessidade de } \\
\text { monitoramento ou atuação } \\
\text { corretiva (5) }\end{array}$ & $\begin{array}{c}\text { Depressões acentuadas } \\
\text { nos taludes, } \\
\text { escorregamentos, } \\
\text { sulcos profundos de } \\
\text { erosão, com potencial } \\
\text { de comprometimento } \\
\text { da segurança (7) }\end{array}$ \\
\hline Eclusa (m) & $\begin{array}{l}\text { Não possui } \\
\text { eclusa (0) }\end{array}$ & $\begin{array}{l}\text { Estruturas civis e } \\
\text { hidroeletromecânicas } \\
\text { bem mantidas e } \\
\text { funcionando (1) }\end{array}$ & $\begin{array}{c}\text { Estruturas civis } \\
\text { comprometidas ou dispo- } \\
\text { sitivos hidroeletromecâ- } \\
\text { nicos com problemas } \\
\text { identificados e com } \\
\text { medidas corretivas em } \\
\text { implantação (2) }\end{array}$ & $\begin{array}{l}\text { Estruturas civis com- } \\
\text { prometidas ou dispositi- } \\
\text { vos hidroeletromecâni- } \\
\text { cos com problemas } \\
\text { identificados e sem me- } \\
\text { didas corretivas (4) }\end{array}$ \\
\hline
\end{tabular}


QUADRO 14: Plano de Segurança da Barragem (PS).

\begin{tabular}{|c|c|c|c|c|c|}
\hline Aspecto & \multicolumn{5}{|c|}{ Descrição da condição } \\
\hline $\begin{array}{l}\text { Existência de documenta- } \\
\text { ção de projeto }(n)\end{array}$ & $\begin{array}{l}\text { Projeto executivo } \\
\text { e "como cons- } \\
\text { truído" (0) }\end{array}$ & $\begin{array}{l}\text { Projeto execu- } \\
\text { tivo ou "como } \\
\text { construído" (2) }\end{array}$ & $\begin{array}{l}\text { Projeto básico } \\
\text { (4) }\end{array}$ & $\begin{array}{l}\text { Anteprojeto } \\
\text { ou Projeto } \\
\text { conceitual } \\
(6) \\
\end{array}$ & $\begin{array}{l}\text { Inexiste docu- } \\
\text { mentação } \\
\text { de projeto (8) }\end{array}$ \\
\hline $\begin{array}{l}\text { Estrutura organizacional e } \\
\text { qualificação técnica dos } \\
\text { profissionais da equipe de } \\
\text { Segurança da Barragem } \\
\text { (o) }\end{array}$ & $\begin{array}{l}\text { Possui estrutura } \\
\text { organizacional } \\
\text { com técnico } \\
\text { responsável pela } \\
\text { segurança da } \\
\text { barragem (0) }\end{array}$ & $\begin{array}{l}\text { Possui técnico } \\
\text { responsável pela } \\
\text { segurança da } \\
\text { barragem (4) }\end{array}$ & $\begin{array}{l}\text { Não possui } \\
\text { estrutura or- } \\
\text { ganizacional e } \\
\text { responsável } \\
\text { técnico pela } \\
\text { segurança da } \\
\text { barragem (8) }\end{array}$ & - & - \\
\hline $\begin{array}{c}\text { Procedimentos de } \\
\text { roteiros de inspeções de } \\
\text { segurança e de monitora- } \\
\text { mento }(p)\end{array}$ & $\begin{array}{l}\text { Possui e aplica } \\
\text { procedimentos de } \\
\text { inspeção e } \\
\text { monitoramento } \\
\text { (0) }\end{array}$ & $\begin{array}{l}\text { Possui e aplica } \\
\text { apenas } \\
\text { procedimentos } \\
\text { de inspeção (3) }\end{array}$ & $\begin{array}{l}\text { Possui e não } \\
\text { aplica } \\
\text { procedimentos } \\
\text { de inspeção e } \\
\text { monitoramen- } \\
\text { to (5) }\end{array}$ & $\begin{array}{l}\text { Não possui e } \\
\text { não aplica } \\
\text { procedimen- } \\
\text { tos para } \\
\text { monitora- } \\
\text { mento e ins- } \\
\text { peções (6) }\end{array}$ & - \\
\hline $\begin{array}{l}\text { Regra operacional dos } \\
\text { dispositivos de descarga } \\
\text { da barragem }(q)\end{array}$ & $\begin{array}{l}\text { Sim ou } \\
\text { Vertedouro tipo } \\
\text { soleira livre }(0)\end{array}$ & Não (6) & - & - & - \\
\hline $\begin{array}{l}\text { Relatórios de inspeção de } \\
\text { segurança com análise e } \\
\text { interpretação }(r)\end{array}$ & $\begin{array}{l}\text { Emite regular- } \\
\text { mente os rela- } \\
\text { tórios }(0)\end{array}$ & $\begin{array}{l}\text { Emite os rela- } \\
\text { tórios sem pe- } \\
\text { riodicidade (3) }\end{array}$ & $\begin{array}{l}\text { Não emite os } \\
\text { relatórios (5) }\end{array}$ & - & - \\
\hline
\end{tabular}

FONTE: ANDERÁOS, ARAÚJO E NUNES, 2013.

\section{QUADRO 15: Dano Potencial Associado (DPA).}

\begin{tabular}{|c|c|c|c|c|}
\hline Aspecto & $\begin{array}{c}\text { Volume total } \\
\text { do Reser- } \\
\text { vatório (a) }\end{array}$ & $\begin{array}{l}\text { Potencial de perdas de } \\
\text { vidas humanas (b) }\end{array}$ & Impacto ambiental (c) & $\begin{array}{l}\text { Impacto socioeconômico } \\
\text { (d) }\end{array}$ \\
\hline $\begin{array}{c}\text { Descrição } \\
\text { da Condição }\end{array}$ & $\begin{array}{c}\text { Pequeno } \leq 5 \\
\text { milhões } \mathrm{m}^{3} \\
\text { (1) }\end{array}$ & $\begin{array}{l}\text { INEXISTENTE (não existem } \\
\text { pessoas } \\
\text { permanentes/residentes ou } \\
\text { temporárias/transitando na } \\
\text { área afetada a jusante da } \\
\text { barragem) (0) }\end{array}$ & $\begin{array}{l}\text { SIGNIFICATIVO (área } \\
\text { afetada da barragem } \\
\text { não representa área de } \\
\text { interesse ambiental, } \\
\text { áreas protegidas em } \\
\text { legislação específica ou } \\
\text { encontra-se totalmente } \\
\text { descaracterizada de } \\
\text { suas condições naturais) } \\
\text { (3) }\end{array}$ & $\begin{array}{c}\text { INEXISTENTE (não } \\
\text { existem quaisquer } \\
\text { instalações e serviços de } \\
\text { navegação na área } \\
\text { afetada por acidente da } \\
\text { barragem) (0) }\end{array}$ \\
\hline
\end{tabular}




\section{QUADRO 15: Dano Potencial Associado (DPA). (CONTINUAÇÃO).}

\begin{tabular}{|c|c|c|c|c|}
\hline \multirow{3}{*}{$\begin{array}{l}\text { Descrição } \\
\text { da Condição }\end{array}$} & $\begin{array}{c}\text { Médio } 5 \\
\text { milhões a } 75 \\
\text { milhões } \mathrm{m}^{3} \\
\text { (2) }\end{array}$ & $\begin{array}{l}\text { POUCO FREQUENTE (não } \\
\text { existem pessoas ocupando } \\
\text { permanentemente a área } \\
\text { afetada a jusante da } \\
\text { barragem, mas existe estra- } \\
\text { da vicinal de uso local) (4) }\end{array}$ & $\begin{array}{l}\text { MUITO SIGNIFICATIVO } \\
\text { (área afetada da } \\
\text { barragem apresenta } \\
\text { interesse ambiental } \\
\text { relevante ou } \\
\text { protegida em legislação } \\
\text { específica) (5) }\end{array}$ & $\begin{array}{l}\text { BAIXO (existe pequena } \\
\text { concentração de } \\
\text { instalações residenciais e } \\
\text { comerciais, agrícolas, } \\
\text { industriais ou de } \\
\text { infraestrutura na área } \\
\text { afetada da barragem ou } \\
\text { instalações portuárias ou } \\
\text { serviços de navegação) } \\
\text { (4) }\end{array}$ \\
\hline & $\begin{array}{c}\text { Grande } 75 \\
\text { milhões a } 200 \\
\text { milhões } \mathrm{m}^{3} \\
\text { (3) }\end{array}$ & $\begin{array}{l}\text { FREQUENTE (não existem } \\
\text { pessoas ocupando } \\
\text { permanentemente a área } \\
\text { afetada a jusante da } \\
\text { barragem, mas existe } \\
\text { rodovia municipal, estadual, } \\
\text { federal ou outro local e/ou } \\
\text { empreendimento de } \\
\text { permanência eventual de } \\
\text { pessoas que poderão ser } \\
\text { atingidas) (8) }\end{array}$ & - & $\begin{array}{c}\text { ALTO (existe grande } \\
\text { concentração de } \\
\text { instalações residenciais e } \\
\text { comerciais, agrícolas, } \\
\text { industriais, de infra- } \\
\text { estrutura e serviços de } \\
\text { lazer e turismo na área } \\
\text { afetada da barragem ou } \\
\text { instalações portuárias ou } \\
\text { serviços de navegação) } \\
\text { (8) }\end{array}$ \\
\hline & $\begin{array}{c}\text { Muito } \\
\text { Grande }>200 \\
\text { milhões } \mathrm{m}^{3} \\
\text { (5) }\end{array}$ & $\begin{array}{l}\text { EXISTENTE (existem pessoas } \\
\text { ocupando permanente- } \\
\text { mente a área afetada a } \\
\text { jusante da barragem, } \\
\text { portanto, vidas humanas } \\
\text { poderão ser atingidas) (12) }\end{array}$ & - & - \\
\hline
\end{tabular}

De acordo com a soma dos pontos de CRI e DPA, determina-se segundo o Quadro 16 o resultado final da avaliação.

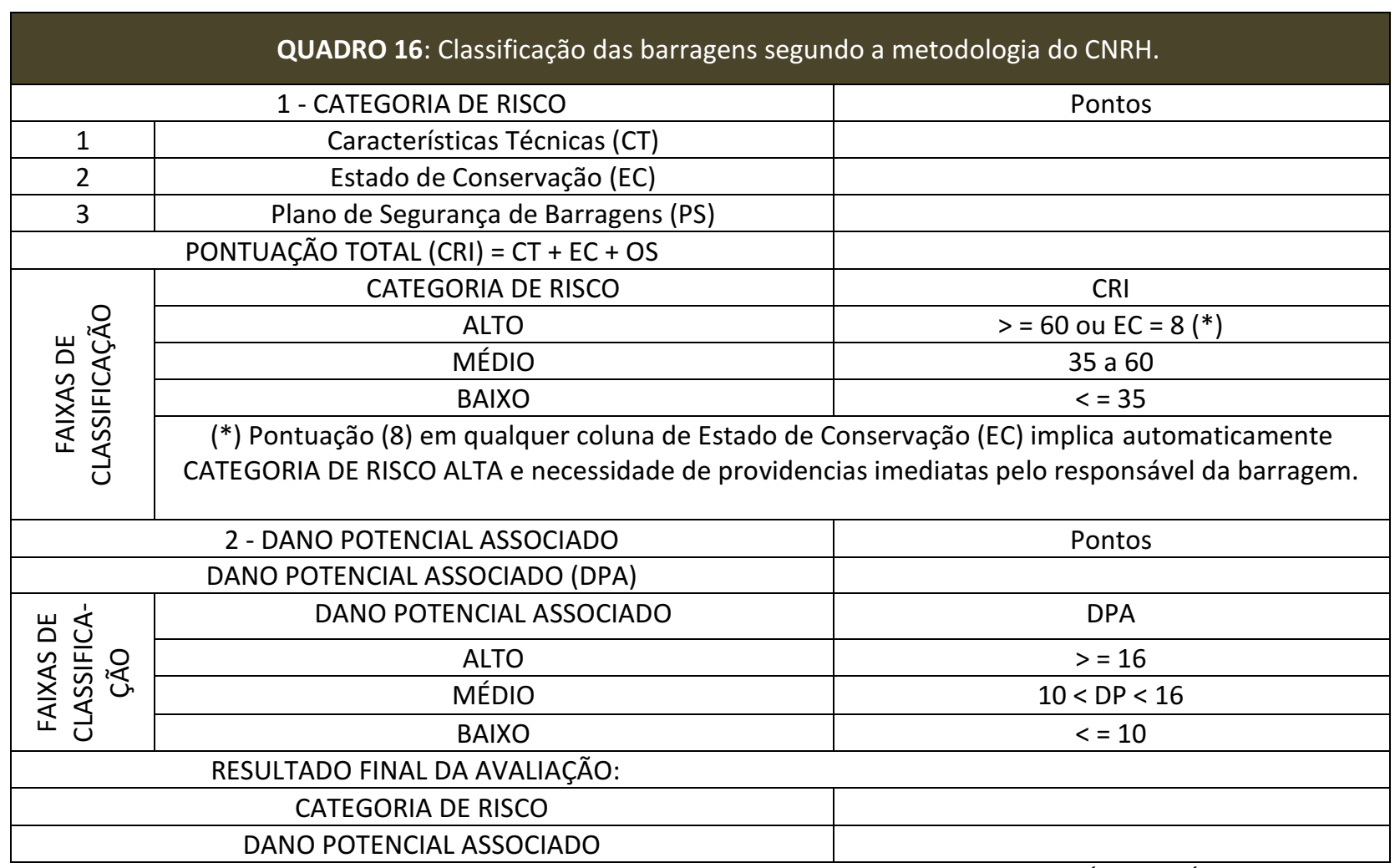


As classes A, B, C e D definidas pela Matriz de Categoria de Risco e Dano Potencial, são apresentadas no Quadro 17, as quais são utilizadas para definir a abrangência do Plano de Segurança da Barragem (PSB) e a periodicidade mínima da Revisão Periódica de Segurança de Barragens (RPSB), definidos através da Resolução no 236 de 30 de janeiro de 2017.

QUADRO 17: Matriz Categoria de Risco e Dano Potencial Associado.

\begin{tabular}{|c|c|c|c|}
\hline \multirow{2}{*}{ CATEGORIA DE RISCO } & \multicolumn{3}{|c|}{ DANO POTENCIAL } \\
& ASSOCIADO \\
\cline { 2 - 4 } & ALTO & MÉDIO & BAIXO \\
\hline ALTO & A & B & C \\
\hline MÉDIO & A & C & D \\
\hline BAIXO & A & D & D \\
\hline
\end{tabular}

FONTE: ANA, 2017

\section{ESTUDO DE CASO}

\subsection{DADOS DA BARRAGEM}

A barragem Malcozinhado é uma barragem de terra homogênea que interrompe o fluxo do riacho Malcozinhado, e está localizada no nordeste brasileiro, mais precisamente no Município de Cascavel-CE a $68 \mathrm{~km}$ de Fortaleza (coordenadas 578.784E e 9.545.914N). A barragem foi construída pela Superintendência de Obras Hidráulicas (SOHIDRA), órgão executor da Secretaria dos Recursos Hídricos do Estado do Ceará (SRH), sendo concluída em novembro de 2002. A obra tem como finalidade principal o abastecimento de água, atendendo à Região Metropolitana de Fortaleza.

O barramento tem altura máxima de 18,34 $\mathrm{m}$, tomada d'água do tipo caixa submersível com tubulação de aço envelopada de concreto de 600 $\mathrm{mm}$ de diâmetro e vertedouro de perfil tipo Creager com $60 \mathrm{~m}$ de extensão. 0 coroamento da barragem tem comprimento de $832 \mathrm{~m}$ com largura de 6 metros.

O maciço foi executado com materiais argilo-arenosos provenientes de jazidas e escavação obrigatória do vertedouro. A proteção do talude de montante é de uma camada de rip-rap e de jusante uma camada de brita, ambos os taludes têm inclinação de $2 \mathrm{H}: 1 \mathrm{~V}$. O sistema de drenagem interno da barragem é constituído de um filtro vertical e tapete drenante horizontal de 1 metro de espessura com um dreno de pé.

A barragem engloba uma área de bacia hidrográfica de $81.000 \mathrm{~km}^{2}$. O reservatório tem capacidade de armazenar $36,55 \mathrm{hm}^{3}$ de água. Vale ressaltar que no dia de realização da inspeção, 19 de agosto de 2016, a cota do nível d'água do açude era de $17,52 \mathrm{~m}$ e o volume era de $5,87 \mathrm{hm}^{3}$, portanto tendo $16,06 \%$ do reservatório ocupado.

Por tratar-se de uma obra financiada com recursos do Banco Mundial, a SRH, por obrigação das normas operacionais do banco, teve que contratar uma junta de consultores de renome nacional na área de barragens (denominado de Painel de Inspeção de Segurança de Barragens (PISB), cuja equipe avaliou o projeto executivo e acompanhou o andamento das obras do início até à fase elaboração do projeto como construído ("as-built") da obra.

\subsection{METODOLOGIA ADOTADA NA PESQUISA}

\subsubsection{Inspeção}

Parte da gestão da segurança cabe ao Agente de Guarda e Inspeção do Reservatório (AGIR) que faz inspeções diárias e é capacitado para solucionar algumas pequenas anomalias que possam surgir na estrutura. Em caso de surgir anomalias que não podem ser solucionadas por este agente, deve este entrar em contato com a gerência regional para a solução.

Para a elaboração deste trabalho, realizou-se uma inspeção formal acompanhada pelo AGIR da barragem, na data de 19 de agosto de 2016, com a finalidade de identificar e fotografar as anomalias presentes na barragem.

\subsubsection{Cálculo da ameaça utilizando a metodologia NPB}

O Cálculo da pontuação total do nível de ameaça utilizando a metodologia NPB da Barragem Malcozinhado em 2016 em comparação ao do ano de 2006 está apresentada na Tabela 1. 
TABELA 1: Comparativo da pontuação NPB.

\begin{tabular}{lccccccc} 
& Peso do & \multicolumn{2}{c}{ Quantidade na lista de Inspeção } & Peso das Quantidades (b) & \multicolumn{2}{c}{ Pontuação NPB (a x b) } \\
\cline { 3 - 7 } NP & NP (a) & 2006 & 2016 & 2006 & 2016 & 2006 & 2016 \\
\hline Nenhum (0) & 0 & 0 & 14 & 0 & 3 & 0 & 0 \\
Atenção (1) & 1 & 0 & 7 & 0 & 2 & 0 & 2 \\
Alerta (2) & 4 & 4 & 12 & 3 & 4 & 12 \\
$\begin{array}{c}\text { Emergência } \\
\text { (3) }\end{array}$ & 9 & 0 & 1 & 0 & 0 & 9 \\
\hline & & \multicolumn{2}{c}{ Total da pontuação NPB da barragem = } & 4 & 23 \\
\hline
\end{tabular}

FONTE: Adaptado de FONTENELLE, 2007

Segundo Fontenelle (2007), a barragem Malcozinhado teve o total da pontuação NPB de 4 pontos, sendo assim classificada de acordo com o Quadro 4 em Aceitável, porém no ano de 2016 a barragem passou a ser classificada em Preocupante pois teve um total da pontuação NPB de 23 pontos. $O$ aumento na ameaça deve-se ao aumento do número de anomalias identificadas no barramento.

\subsection{Cálculo do risco utilizando a metodologia COGERH}

No cálculo do risco da barragem utilizando esta metodologia, considera-se o mesmo valor de $\mathrm{P}$ para os anos de 2006 e 2016, pois trata-se de aspectos relacionados às características de projeto.
A Quadro 18 mostra para a Periculosidade a pontuação 22, portanto trata-se de uma Periculosidade Significativa.

O Quadro 19 apresenta o comparativo entre a vulnerabilidade contabilizada no ano de 2006 e a de 2016. É possível observar uma leve diminuição, passando de 12 para 10. Mas ambas são dadas como Baixa a Moderada pois encontram-se no intervalo de 5 a 20 pontos.

Não houve aumento significativo de população à jusante e os outros aspectos analisados referem-se à características de projeto, portanto considera-se o mesmo valor de 1,33 correspondente à I, para os anos de 2006 e 2016, como apresentado no Quadro 20.

\begin{tabular}{|c|c|}
\hline 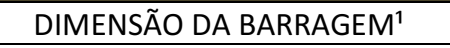 & Altura 10 a $20 \mathrm{~m}$ e comprimento $<200 \mathrm{~m}(3)$ \\
\hline VOL. TOTAL DO RESERVATÓRIO² & Pequeno $<20 \mathrm{hm}^{3}(3)$ \\
\hline TIPO DE BARRAGEM ${ }^{3}$ & Terra (10) \\
\hline TIPO DE FUNDAÇÃO ${ }^{4}$ & Solo residual / Aluvião até 4m (5) \\
\hline VAZÃO DE PROJETO ${ }^{5}$ & Decamilenar (1) \\
\hline TOTAL = & 22 \\
\hline
\end{tabular}

FONTE: FONTENELLE, 2007

QUADRO 19: Comparativo entre os anos 2006 e 2016 quanto à Vulnerabilidade (V) da Barragem Malcozinhado.

\begin{tabular}{|c|c|c|}
\hline ANO & 2006 & 2016 \\
\hline TEMPO DE OPERAÇÃO ${ }^{6}$ & $<5$ anos (3) & 10 a 30 anos (1) \\
\hline EXISTÊNCIA DE PROJETO (AS BUILT $)^{7}$ & Existem projetos "as built" (3) & $\begin{array}{l}\text { Existem projetos "as built" e } \\
\text { avaliação do desempenho (1) }\end{array}$ \\
\hline $\begin{array}{c}\text { CONFIABILIDADE DAS ESTRUTURAS } \\
\text { VERTEDOURAS }{ }^{8}\end{array}$ & Muito Satisfatória (2) & Satisfatória (3) \\
\hline TOMADA DE ÁGUA9 & Satisfatória, Controle a jusante (2) & $\begin{array}{c}\text { Satisfatória, Controle a } \\
\text { montante (1) }\end{array}$ \\
\hline PERCOLAÇÃO ${ }^{10}$ & $\begin{array}{l}\text { Totalmente controlada pelo } \\
\text { sistema de drenagem (1) }\end{array}$ & $\begin{array}{l}\text { Totalmente Controlada Pelo } \\
\text { sistema de drenagem (1) }\end{array}$ \\
\hline $\begin{array}{l}\text { DEFORMAÇÕES/ AFUNDAMEN-TOS ASSENTA- } \\
\text { MENTOS }{ }^{11}\end{array}$ & Inexistente (0) & Inexistente (0) \\
\hline DETERIORAÇÃO DOS TALUDES/ PARAMENTOS 12 & Inexistente (1) & $\begin{array}{c}\text { Falhas no rip-rap e na proteção } \\
\text { de Jusante (3) }\end{array}$ \\
\hline TOTAL = & 12 & 10 \\
\hline
\end{tabular}




\begin{tabular}{|c|c|c|}
\hline VOL. ÚTIL ${ }^{1} \mathrm{hm}^{3}$ (A) & POPULAÇÃO A JUSANTE (B) & CUSTO DA BARRAGEM ${ }^{(\mathrm{C})}$ \\
\hline Baixo $(1)<200$ & Média $(2,0)$ & Pequeno $(1,0)$ \\
\hline \multicolumn{3}{|l|}{ Nota: } \\
\hline \multicolumn{3}{|l|}{ (A)...... } \\
\hline \multicolumn{3}{|l|}{$(B) \ldots \ldots \ldots$} \\
\hline (C) $\ldots \ldots \ldots$ & & \\
\hline
\end{tabular}

FONTE: Adaptado de FONTENELLE, 2007.

Por fim, houve uma pequena diminuição no PR ao longo de 10 anos, passando de 22,61 em 2006 para 21,28 em 2016, mas ainda pertencendo à Classe $D$, isto é, risco baixo. Observa-se nos Quadros 21, 22 e 23 a frequência de inspeções, os requisitos mínimos quanto à manutenção e o critério para instrumentação, respectivamente, recomendados pela COGERH à barragens que pertençam a esta classe de risco.

\section{QUADRO 21: Frequência de Inspeções recomendada à Barragem Malcozinhado.}

\begin{tabular}{|c|c|}
\hline \multirow{2}{*}{ TIPO DE INSPEÇÃO } & Classificação da Barragem \\
\cline { 2 - 2 } & D \\
\hline Rotina & $2 /$ ano (semestral) \\
\hline Periódica & $1 / 2$ anos (relatório simplificado) \\
\hline Formal & $1 / 15$ anos \\
\hline Especial & Em oportunidades tais como cheias excepcionais, rebaixamento rápido do reservatório, \\
sismos etc.
\end{tabular}

FONTE: Adaptado de FONTENELLE, 2007.

QUADRO 22: Requisitos mínimos quanto à manutenção da Barragem Malcozinhado.

\begin{tabular}{|c|c|}
\hline CLASSE DA BARRAGEM & REQUISITOS MÍNIMOS \\
\hline D & P- pequenas deficiências \\
\hline \multicolumn{2}{|c|}{ FONTE: Adaptado de FONTENELLE, 2007.}
\end{tabular}

QUADRO 23: Critério para Instrumentação da Barragem Malcozinhado.

\begin{tabular}{|c|c|c|}
\hline \multicolumn{2}{|c|}{ Altura da Barragem (m) } & 10 a 20 \\
\hline \multirow{2}{*}{ Deslocamentos } & Superficiais & Opcional \\
\hline & Internos & - \\
\hline \multicolumn{2}{|c|}{ Tensões totais } & - \\
\hline \multicolumn{2}{|c|}{ Vazões } & Opcional \\
\hline \multicolumn{2}{|c|}{ Piezômetros } & Opcional \\
\hline \multicolumn{2}{|c|}{ Sismologia } & - \\
\hline
\end{tabular}

FONTE: Adaptado de FONTENELLE, 2007. 


\subsection{Cálculo do risco utilizando a metodologia do CNRH}

É possível visualizar nos Quadros 24, 25, 26 e 27 a pontuação quanto aos aspectos: CT, EC, PS e DPA, necessários para o resultado final da avaliação utilizando a metodologia $\mathrm{CNRH}$.

No cálculo do CT adota-se os mesmos valores aos parâmetros considerados, pois estes estão relacionados ao projeto da barragem, exceto em relação à idade da barragem na data da inspeção. Em que se adota um valor maior para o período de primeiras solicitações, correspondente aos 5 anos iniciais de operação.

Considerou-se o mesmo valor de DPA para ambos os anos pois se trata de aspectos de projeto e não houve aumento considerável de ocupação à jusante da barragem no período estudado.

QUADRO 24: CT da Barragem Malcozinhado.

\begin{tabular}{|c|c|c|}
\hline \multirow{2}{*}{ ASPECTO ANALISADO } & \multicolumn{2}{|c|}{ DESCRIÇÃO DA CARACTERÍSTICA TÉCNICA } \\
\hline & 2006 & 2016 \\
\hline Altura (a) & $15 \mathrm{~m}<$ Altura $<30 \mathrm{~m}(1)$ & $15 \mathrm{~m}<$ Altura $<30 \mathrm{~m}(1)$ \\
\hline Comprimento (b) & Comprimento > 200m (3) & Comprimento > 200m (3) \\
\hline $\begin{array}{l}\text { Tipo de Barragem quanto ao } \\
\text { material de construção (c) }\end{array}$ & $\begin{array}{c}\text { Terra Homogênea / Enrocamento / } \\
\text { Terra Enrocamento (3) }\end{array}$ & $\begin{array}{c}\text { Terra Homogênea / Enrocamento / } \\
\text { Terra Enrocamento (3) }\end{array}$ \\
\hline Tipo de Fundação (d) & $\begin{array}{l}\text { Rocha altamente dura com trata- } \\
\text { mento ( } 2)\end{array}$ & $\begin{array}{l}\text { Rocha altamente dura com trata- } \\
\text { mento ( } 2 \text { ) }\end{array}$ \\
\hline Idade da Barragem (e) & $\begin{array}{c}<5 \text { anos ou }>50 \text { anos ou sem } \\
\text { informação (4) }\end{array}$ & Entre 10 e 30 anos (2) \\
\hline Vazão de Projeto (f) & $\begin{array}{c}\text { Decamilenar ou CMP (Cheia Máxima } \\
\text { Provável) }-\mathrm{TR}=10.000 \text { anos }(3)\end{array}$ & $\begin{array}{c}\text { Decamilenar ou CMP (Cheia Máxima } \\
\text { Provável) }-\mathrm{TR}=10.000 \text { anos }(3)\end{array}$ \\
\hline TOTAL = & 16 & 14 \\
\hline
\end{tabular}

FONTE: Adaptado de ANDERÁOS, ARAÚJO E NUNES, 2013.

\begin{tabular}{|c|c|c|}
\hline \multicolumn{3}{|c|}{ QUADRO 25: EC da Barragem Malcozinhado. } \\
\hline ASPECTO & \multicolumn{2}{|c|}{ DESCRIÇÃO DA CARACTERÍSTICA TÉCNICA } \\
\hline ANALISADO & 2006 & 2016 \\
\hline $\begin{array}{l}\text { Confiabilidade das } \\
\text { Estruturas } \\
\text { Extravasoras (g) }\end{array}$ & $\begin{array}{l}\text { Estruturas civis e hidroeletro- } \\
\text { mecânicas em pleno funciona- } \\
\text { mento / canais de aproximação ou } \\
\text { de restituição ou vertedouro (tipo } \\
\text { soleira livre) desobstruídos (0) }\end{array}$ & $\begin{array}{l}\text { Estruturas civis e hidroeletromecânicas preparadas } \\
\text { para a operação, mas sem fontes de suprimento de } \\
\text { energia de emergência / canais ou vertedouro (tipo } \\
\text { soleira livre) com erosões ou obstruções, porém sem } \\
\text { riscos a estrutura vertente. (4) }\end{array}$ \\
\hline $\begin{array}{l}\text { Confiabilidade das } \\
\text { Estruturas de } \\
\text { Adução (h) }\end{array}$ & $\begin{array}{l}\text { Estruturas civis e dispositivos } \\
\text { hidroeletromecânicos em condi- } \\
\text { ções adequadas de manutenção e } \\
\text { funcionamento (0) }\end{array}$ & $\begin{array}{l}\text { Estruturas civis comprometidas ou dispositivos } \\
\text { hidroeletromecânicos com problemas identificados, } \\
\text { com redução de capacidade de vazão e sem medidas } \\
\text { corretivas (6) }\end{array}$ \\
\hline Percolação (i) & $\begin{array}{l}\text { Percolação totalmente } \\
\text { controlada pelo sistema de } \\
\text { drenagem (0) }\end{array}$ & $\begin{array}{l}\text { Percolação totalmente } \\
\text { controlada pelo sistema de drenagem (0) }\end{array}$ \\
\hline $\begin{array}{l}\text { Deformações e } \\
\text { Recalques (j) }\end{array}$ & Inexistente (0) & Inexistente (0) \\
\hline $\begin{array}{l}\text { Deterioração dos } \\
\text { taludes / } \\
\text { paramentos (I) }\end{array}$ & Inexistente (0) & $\begin{array}{c}\text { Falhas na proteção dos taludes e para- mentos, } \\
\text { presença de arbustos de pequena extensão e impacto } \\
\text { nulo. (1) }\end{array}$ \\
\hline Eclusa (m) & Não possui eclusa (0) & Não possui eclusa (0) \\
\hline TOTAL= & 0 & 11 \\
\hline
\end{tabular}

FONTE: Adaptado de ANDERÁOS, ARAÚJO E NUNES, 2013. 
QUADRO 26: PS da Barragem Malcozinhado.

\begin{tabular}{|c|c|c|}
\hline \multirow{2}{*}{ ASPECTO ANALISADO } & \multicolumn{2}{|c|}{ DESCRIÇÃO DA CONDIÇÃO } \\
\hline & 2006 & 2016 \\
\hline $\begin{array}{l}\text { Existência de documentação de projeto } \\
\qquad(\mathrm{n})\end{array}$ & $\begin{array}{l}\text { Projeto executivo e "como cons- } \\
\text { truído" (0) }\end{array}$ & $\begin{array}{l}\text { Projeto executivo e "como } \\
\text { construído" (0) }\end{array}$ \\
\hline $\begin{array}{l}\text { Estrutura organizacional e qualificação } \\
\text { técnica dos profissionais da equipe de } \\
\text { Segurança da Barragem (o) }\end{array}$ & $\begin{array}{c}\text { Possui estrutura organizacional com } \\
\text { técnico responsável pela segurança } \\
\text { da barragem (0) }\end{array}$ & $\begin{array}{c}\text { Possui estrutura organizacional com } \\
\text { técnico responsável pela segurança } \\
\text { da barragem }(0)\end{array}$ \\
\hline $\begin{array}{l}\text { Procedimentos de roteiros de inspeções } \\
\text { de segurança e de monitoramento ( } p)\end{array}$ & $\begin{array}{l}\text { Possui e aplica procedimentos de } \\
\text { inspeção e monitoramento (0) }\end{array}$ & $\begin{array}{l}\text { Possui e aplica procedimentos de } \\
\text { inspeção e monitoramento (0) }\end{array}$ \\
\hline $\begin{array}{c}\text { Regra operacional dos dispositivos de } \\
\text { descarga da barragem (q) }\end{array}$ & $\begin{array}{c}\text { Sim ou Vertedouro tipo soleira livre } \\
(0)\end{array}$ & $\begin{array}{c}\text { Sim ou Vertedouro tipo soleira livre } \\
(0)\end{array}$ \\
\hline $\begin{array}{l}\text { Relatórios de inspeção de segurança com } \\
\text { análise e interpretação (r) }\end{array}$ & Emite regularmente os relatórios (0) & Emite regularmente os relatórios (0) \\
\hline TOTAL = & 0 & 0 \\
\hline
\end{tabular}

FONTE: Adaptado de ANDERÁOS, ARAÚJO E NUNES, 2013.

\begin{tabular}{|c|c|}
\hline \multicolumn{2}{|r|}{ QUADRO 27: DPA da Barragem Malcozinhado. } \\
\hline ASPECTO ANALISADO & DESCRIÇÃO DA CONDIÇÃO \\
\hline $\begin{array}{l}\text { Volume total do } \\
\text { Reservatório (a) }\end{array}$ & Médio: 5 milhões a 75 milhões $\mathrm{m}^{3}$ (2) \\
\hline $\begin{array}{l}\text { Potencial de perdas de } \\
\text { vidas humanas (b) }\end{array}$ & $\begin{array}{l}\text { FREQUENTE (não existem pessoas ocupando permanentemente a área afetada a jusante da } \\
\text { barragem, mas existe rodovia municipal, estadual, federal ou outro local e/ou } \\
\text { empreendimento de permanência eventual de pessoas que poderão ser atingidas) (8) }\end{array}$ \\
\hline Impacto ambiental (c) & $\begin{array}{l}\text { SIGNIFICATIVO (área afetada da barragem não representa área de interesse ambiental, áreas } \\
\text { protegidas em legislação específica ou encontra-se totalmente descaracterizada de suas } \\
\text { condições naturais) (3) }\end{array}$ \\
\hline $\begin{array}{c}\text { Impacto } \\
\text { socioeconômico }(d)\end{array}$ & $\begin{array}{l}\text { INEXISTENTE (não existem quaisquer instalações e serviços de navegação na área afetada por } \\
\text { acidente da barragem) (0) }\end{array}$ \\
\hline TOTAL $=$ & 13 \\
\hline
\end{tabular}

FONTE: Adaptado de ANDERÁOS, ARAÚJO E NUNES, 2013.

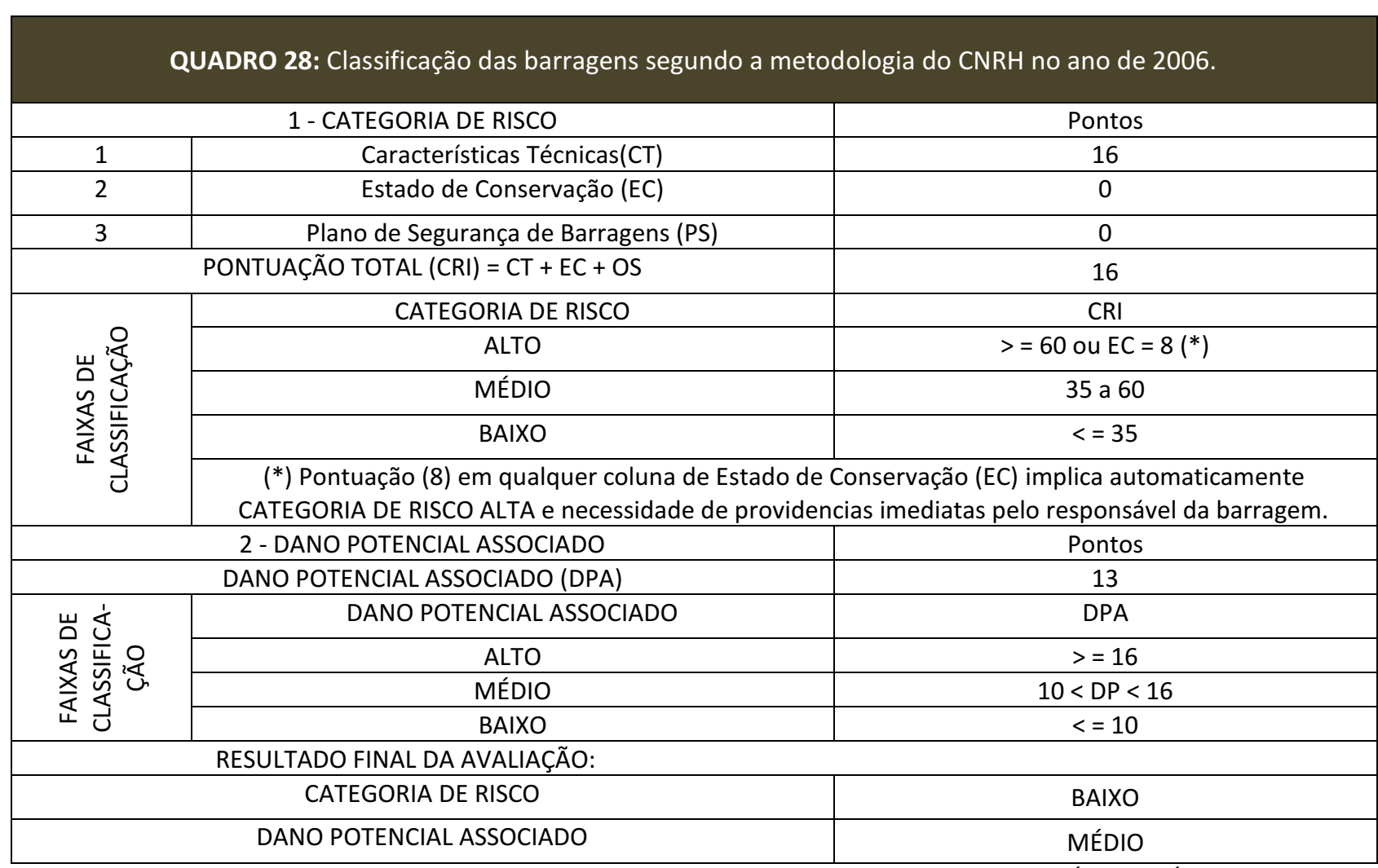


QUADRO 29: Classificação das barragens segundo a metodologia do CNRH no ano de 2016.

\begin{tabular}{|c|c|c|}
\hline \multicolumn{2}{|r|}{1 - CATEGORIA DE RISCO } & Pontos \\
\hline 1 & Características Técnicas(CT) & 14 \\
\hline 2 & Estado de Conservação (EC) & 11 \\
\hline 3 & Plano de Segurança de Barragens (PS) & 0 \\
\hline \multicolumn{2}{|r|}{ PONTUAÇÃO TOTAL (CRI) = CT + EC + OS } & 25 \\
\hline \multirow{5}{*}{ 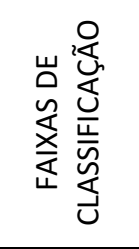 } & CATEGORIA DE RISCO & CRI \\
\hline & ALTO & $>=60$ ou $\mathrm{EC}=8(*)$ \\
\hline & MÉDIO & 35 a 60 \\
\hline & BAIXO & $<=35$ \\
\hline & \multicolumn{2}{|c|}{$\begin{array}{l}\left({ }^{*}\right) \text { Pontuação }(8) \text { em qualquer coluna de Estado de Conservação (EC) implica automaticamente } \\
\text { CATEGORIA DE RISCO ALTA e necessidade de providencias imediatas pelo responsável da barragem. }\end{array}$} \\
\hline \multicolumn{2}{|r|}{2 - DANO POTENCIAL ASSOCIADO } & Pontos \\
\hline \multicolumn{2}{|r|}{ DANO POTENCIAL ASSOCIADO (DPA) } & 13 \\
\hline \multirow{4}{*}{ 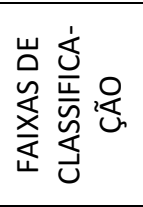 } & DANO POTENCIAL ASSOCIADO & DPA \\
\hline & ALTO & $>=16$ \\
\hline & MÉDIO & $10<\mathrm{DP}<16$ \\
\hline & BAIXO & $<=10$ \\
\hline \multicolumn{3}{|c|}{ RESULTADO FINAL DA AVALIAÇÃO: } \\
\hline \multicolumn{2}{|r|}{ CATEGORIA DE RISCO } & BAIXO \\
\hline \multicolumn{2}{|r|}{ DANO POTENCIAL ASSOCIADO } & MÉDIO \\
\hline
\end{tabular}

FONTE: Adaptado de ANDERÁOS, ARAÚJO E NUNES, 2013.

Conforme os Quadros 17, 28 e 29 a Barragem Malcozinhado, em 2006 e 2016, pertence à classe $\mathrm{D}$ de acordo com a Matriz de Categoria de Risco e Dano Potencial Associado, pois as faixas de classificação quanto aos parâmetros CRI e ao DPA são Baixo e Médio, respectivamente. Portanto estabelece-se para esta classe uma Revisão Periódica de Segurança de Barragens a cada 12 anos e a abrangência do Plano de Segurança de Barragens sendo os Volumes I, II, III, IV e V, segundo a Resolução da ANA No 236 de 30 de janeiro de 2017.

\section{ANÁLISE DOS RESULTADOS}

No estudo de caso utiliza-se a metodologia NPB para a análise do nível de ameaça, além de duas metodologias de avaliação de risco, baseadas na inspeção realizada em 2016.

$\mathrm{Na}$ análise da ameaça, utilizando a metodologia NPB, houve uma mudança significativa quanto à classe da barragem, passando de Aceitável, em 2006, para Preocupante, em 2016, haja vista que esta metodologia considera apenas o número de anomalias e seu nível de perigo, isto é, o estado de conservação da barragem. Isto se deve ao aumento no número de anomalias identificadas durante a inspeção na barragem, passando de 4 em 2006 para 34 em 2016. A Figura 1 apresenta o comparativo dos índices do NPB.

Quanto à metodologia da COGERH, observou-se uma pequena redução no Potencial de Risco da barragem no período estudado. $O$ índice de risco superior em 2006 deve-se ao fato de ser atribuído um peso maior a uma barragem de até cinco anos de operação, tendo em vista que este período corresponde à primeira solicitação da barragem, isto é, ao primeiro enchimento, à saturação do maciço e ao primeiro vertimento. $\mathrm{Na}$ Figura 2 é possível visualizar o comparativo entre os anos 2006 e 2016 dos índices da metodologia da COGERH.

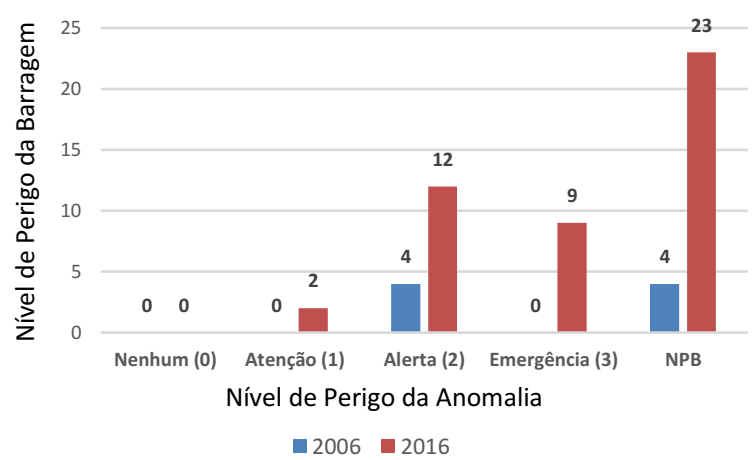

FIGURA 1: Comparativo dos índices da metodologia NPB. FONTE: Elaborado pelos Autores, 2017. 


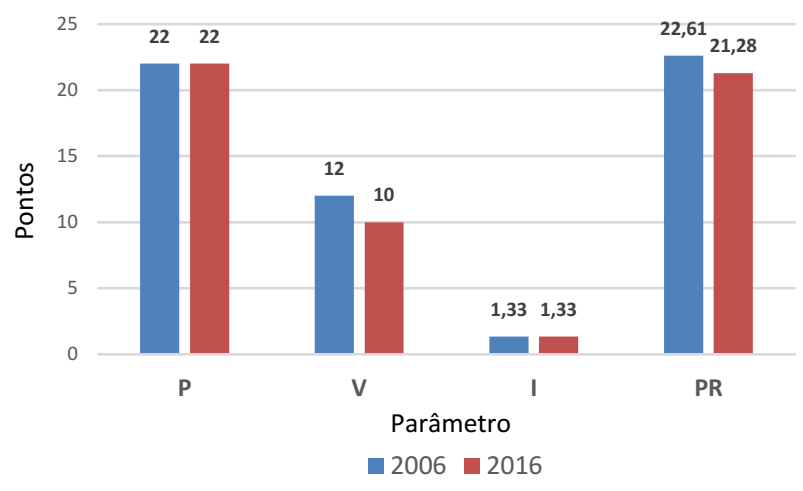

FIGURA 2: Comparativo dos índices da metodologia da COGERH.

FONTE: Elaborado pelos Autores, 2017.

Na metodologia do CNRH, observa-se no período um aumento no $\mathrm{CRI}$, dado principalmente devido ao estado precário dos equipamentos hidromecânicos, mas este ainda permanece classificado como Baixo. Na Figura 3 observa-se o comparativo do valor dos aspectos estudados nesta metodologia nos anos de 2006 e 2016.

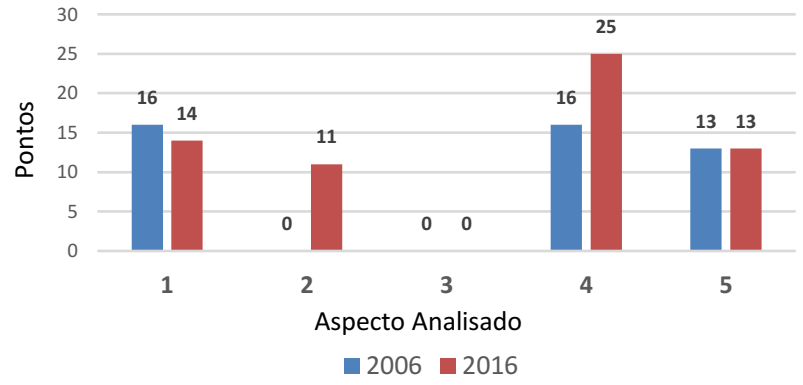

FIGURA 3: Comparativo dos índices da metodologia do CNRH FONTE: Elaborado pelos Autores, 2017.

Nesse contexto, considerando que o risco é o produto da Ameaça com a Consequência, apesar da inspeção atual ter indicado o aumento da Ameaça no período considerado, as avaliações de risco não apresentaram variação quanto à classificação. Este resultado pode estar relacionado ao fato de que em 2016 o nível do reservatório estava mais baixo que em 2006, e, portanto, a consequência é menor, as anomalias identificadas na inspeção não têm um peso considerável nas avaliações de risco e a barragem já ter ultrapassado o período de primeiras solicitações.

\section{CONCLUSÃO}

Foram utilizadas metodologias de avaliação de risco como ferramenta para acompanhar a condição de segurança do barramento e, caso necessário, deve-se traçar uma estratégia para diminuir o risco verificado.

Verificou-se que o nível de ameaça estabelecido a partir da metodologia NPB aplicado ao presente estudo de caso passou de Aceitável para Preocupante em função do aumento do número de anomalias de 4, em 2006, para 34, em 2016.

As metodologias de avaliação de risco apresentaram a classificação de risco semelhante ao longo de dez anos, como Baixo ou Médio.

Apesar do nível de ameaça determinado pelo NPB no presente estudo de caso ter aumentado no período, não houve variação na classificação de risco segundo as metodologias adotadas. Além disso, o volume do reservatório na condição atual se apresentava mais baixo ao considerado em 2006, desta forma, há a redução dos impactos no caso de ruptura, e também ao fato da barragem já ter ultrapassado o período operacional de 5 anos correspondente as primeiras solicitações.

Portanto, devido ao fato da Barragem Malcozinhado ser uma barragem de pequeno a médio porte, relativamente jovem, inspecionada regularmente pela COGERH e projetada e construída com controles rígidos do PISB, pode-se afirmar que as metodologias aplicadas neste trabalho foram satisfatórias.

\section{REFERÊNCIAS BIBLIOGRÁFICAS}

ANA. (2017). Resolução no 236/2017. Disponível em: <http://arquivos.ana.gov.br/resolucoes/2017/2362017.pdf> Acesso em: 29/05/2017.

ANDERÁOS, A.; ARAÚJO, L. M. N.; NUNES, C. M. Classificação de Barragem quanto à Categoria de Risco e ao Dano Potencial Associado - Um Exercício. XX Simpósio Brasileiro de Recursos Hídricos, Bento Gonçalves - RS, 2013.

BRASIL. Ministério da integração Nacional. Manual de Segurança e Inspeção de Barragens. Brasília. 2002. 148p.

BRASIL. AGÊNCIA NACIONAL DE ÁGUAS (Org.). Relatório de Segurança de Barragens 2011. Brasília, 2012. 
FONTENELLE, A. S. Proposta Metodológica de Avaliação de Riscos em Barragens no Nordeste Brasileiro - estudo de caso: barragens do estado do Ceará. Tese (Doutorado) - Programa de Pós-Graduação em Recursos Hídricos Centro de Tecnologia, Universidade Federal do Ceará, Fortaleza, 2007.

INAG (INSTITUTO DA ÁGUA). Curso de Exploração e Segurança de Barragens. A.A. Balkema Publishers, Lisboa, 2001. 710p.

MEDEIROS, C. H. de A. C. How Risky can be a Risk Assessment Technique on Safety Dams Evaluation - A Critical Review. In: 73rd Annual Meeting, ICOLD, Teerã, 2005.

MELLO, F. M. (Org.). A história das barragens no Brasil, Séculos XIX, XX e XXI: cinquenta anos do Comitê Brasileiro de Barragens. Rio de Janeiro: CBDB, 2011. Disponível em: <http://www.cbdb.org.br/documentos/a_historia_das_ barragens_no_brasil.pdf>. Acesso em: 16 ago. 2016.

MENESCAL, R. A.; FONTENELLE, A. S.; OLIVEIRA, S. K. F; VIEIRA, V. P. P. B. Ações de Segurança de Barragens no Estado do Ceará. XXIV Seminário Nacional de Grandes Barragens, Anais, Fortaleza - CE. 2001.

MENESCAL, R. A. Gestão de Segurança de Barragens no Brasil - Proposta de um sistema integrado, descentralizado, transparente e participativo. Tese (Doutorado) - Departamento de Engenharia Hidráulica e Ambiental, Fortaleza - CE, 2009.

SILVEIRA, J.F.; CARNEIRO, E. F.; PÍNFARI J. C. O Grande Potencial Apresentado pela Análise de Risco de Usinas Hidrelétricas - A Experiência da CESP. XXVII Seminário Nacional De Grandes Barragens. Belém - Pa, 2007. 